\title{
Adhesive and hydrophobic properties of Escherichia coli from the rectal mucosa of patients with ulcerative colitis
}

\author{
M Gillian Hartley, M J Hudson, E T Swarbrick, A E Gent, M D Hellier, R H Grace
}

\begin{abstract}
The adherent properties and hydrophobicity of Escherichia coli isolates have been compared from the rectal mucosa of patients with active and inactive ulcerative colitis and from a control patient group. Patients with active colitis were colonised less frequently and with lower numbers of $E$ coli than were control patients. Mannose resistant adhesion to HEp-2 cells was determined for 124 isolates of $E$ coli and surface hydrophobicity was estimated by salt agglutination in 96 of these isolates. There was no significant difference in the distribution of adherent strains between the colitis patient groups or with disease activity. $E$ coli from the control patients were marginally less adhesive than those from colitics. The hydrophobicity of isolates did not differ significantly between colitic and control groups nor were there significant differences correlated with disease activity. Furthermore, for these mucosal $E$ coli isolates, hydrophobicity and mannose resistant adhesion were unrelated characteristics.

(Gut 1993; 34: 63-67)
\end{abstract}

It is commonly believed that the intestinal microflora plays some role in the pathogenesis of ulcerative colitis but no aetiological agent has been identified and there are only relatively minor alterations to the balance of the faecal flora. ${ }^{1}$ In some studies increased numbers of Escherichia coli have been reported in the faeces of colitic patients in comparison with control groups of patients ${ }^{2}$ and isolates from colitics are also more likely to produce haemolysin and necrotoxin. ${ }^{3}$ Serum agglutinating antibodies against $E$ coli are found more commonly and at higher titres in patients with ulcerative colitis. ${ }^{4}$

Dickinson and colleagues ${ }^{5}$ reported that $E$ coli from the faeces of colitics were markedly more adherent to HeLa cells in an in vitro assay than isolates from non-colitic control patients and showed that this adhesion was mannose resistant. Burke and Axon $^{6}$ described an alternative assay using human buccal epithelial cells with which they confirmed that enterobacteria from colitics were 'stickier' than those from healthy donors. Subsequently, these authors have shown that faecal $E$ coli from colitics were more hydrophobic than those from non-colitics. ${ }^{7}$ Surface hydrophobicity has been shown to be correlated with adherence in $E$ coli associated with gastroenteritis and pyelonephritis. ${ }^{89}$

The significance of 'sticky' $E$ coli in the pathogenesis of ulcerative colitis remains unclear but their presence in stools of colitic patients does not appear to be as a result of treatment. ${ }^{10}$ Interestingly, oral adjunctive treatment with tobramycin results in significant clinical improvement in patients with ulcerative colitis compared with a comparable group of patients given placebo." The effects of the treatment on the faecal flora were not reported but this poorly absorbed aminoglycoside would be expected to deplete or eradicate intestinal $E$ coli.

We have previously characterised the rectal mucosa associated microflora of patients with ulcerative colitis. ${ }^{12}$ We isolated enterobacteria, usually $E$ coli, less frequently and in lower numbers from patients with newly diagnosed active colitis or active colitis on relapse than from patients with quiescent colitis. As it might be argued that this microflora is more likely to exert pathogenic or protective effects in the intestine than the lumen flora, we were interested to determine the adherent and hydrophobic properties of our mucosal $E$ coli isolates by techniques comparable with those used by others studying faecal isolates.

\section{Methods}

PATIENTS

Rectal mucosal biopsy samples were taken from 25 patients presenting with their first episode of ulcerative colitis (new colitis), 20 patients with active relapse of ulcerative colitis, and 44 patients with quiescent ulcerative colitis. Patients with active colitis were reexamined after three and 12 weeks of treatment. Biopsy samples were also taken from a control group of 15 patients with irritable bowel syndrome or haemorrhoids and in whom inflammatory bowel disease had been excluded. Experimental protocols were approved by local Ethics Committees and informed consent was obtained; biopsy procedures were performed at routine sigmoidoscopy. Tissue samples were snap frozen in liquid nitrogen or on dry ice in a cryoprotective broth and stored frozen. ${ }^{12}$

\section{MICROBIOLOGY}

$E$ coli isolates were collected during studies of the rectal mucosa associated microflora; the methods and anaerobic precautions used for the isolation and characterisation of this flora are detailed elsewhere. ${ }^{12}$ Briefly, each biopsy sample was washed thoroughly in three changes of diluent to remove faeces and adherent mucus. Tissue associated microbes were liberated by maceration and cultured quantitatively on a range of bacteriological media. $E$ coli and other enterobacteria were isolated on either Columbia 
horse blood or MacConkey agars (Oxoid Ltd) incubated aerobically or microaerobically at $37^{\circ} \mathrm{C}$ for between 18 and 48 hours. Counts were expressed as $\log _{10}$ enterobacteria/g wet weight of biopsy tissue. Isolates were identified using biochemical galleries (Sensititre AP60, Radiometer (UK) Ltd or API 20E, API-bioMérieux (UK) Ltd) but were not serotyped routinely. Strains were stored frozen in cryoprotective broth for subsequent adhesion and hydrophobicity assays. The number of strains of $E$ coli from each patient examined for these properties was determined by the variety of colonial or biochemical phenotypes present.

Control $E$ coli strains for adhesion and hydrophobicity assays were obtained from the Division of Enteric Pathogens, Central Public Health Laboratory, London. Enteropathogenic (EPEC) strains E851/71 (0142:H6) and E2348/69 (0127:H6) exhibited both mannose resistant adherence and the EPEC adherence factor phenotype $\left(\mathrm{EAF}^{+}\right)$; strain $\mathrm{Scl} 3(01: \mathrm{H} 7)$ was non-adherent. Strains E851/71 and Sc13 had been included as controls in studies of faecal E coli. ${ }^{67}$

\section{ADHESION STUDIES: HUMAN BUCCAL EPITHELIAL} CELLS

Buccal epithelial cells from eight healthy laboratory staff were prepared using established methods. ${ }^{6}$ Briefly, cells scraped from the buccal mucosa were dispersed in phosphate buffered saline $(2 \mathrm{mM}, \mathrm{pH} 7 \cdot 4)$, washed thrice by centrifugation to remove contaminating salivary flora and resuspended to circa $10^{5}$ cells $/ \mathrm{ml}$ in phosphate buffered saline with D-mannose (1\%).

Overnight cultures of $E$ coli on nutrient agar slopes were gently resuspended in phosphate buffered saline with D-mannose to a standard turbidity (MacFarland's no 9). Equal volumes of bacterial and cell suspensions were mixed and shaken gently at room temperature for 30 minutes. The buccal cells were deposited by vacuum onto a membrane filter $(5 \mu \mathrm{m}$ pore size, Millipore Ltd) and washed free of unbound bacteria with phosphate buffered saline. Impression smears of the filters on glass slides were air dried, acetone fixed and Gram stained. The percentage of buccal epithelial cells with $>50$ adherent Gram negative bacilli was recorded.

ADHESION STUDIES: HEp-2 CELLS

HEp-2 (ATCC CCL 23), obtained from the European Collection of Animal Cell Cultures (ECACC, PHLS - CAMR, Salisbury), were maintained in Eagle's Minimum Essential Medium (MEM, Gibco Ltd) containing Earle's salts, foetal calf serum $(10 \%)$ and antibiotics ${ }^{13}$ incubated at $37^{\circ} \mathrm{C}$ in humidified atmospheres of either $10 \% \mathrm{CO}_{2}$ in air or $10 \% \mathrm{CO}_{2}, 5 \% \mathrm{O}_{2}$ in nitrogen.

HEp-2 cells were transferred to tissue culture treated microplates with $15 \mathrm{~mm}$ wells, each containing a sterile $13 \mathrm{~mm}$ glass coverslip. The cells were grown in antibiotic free medium for two days to give a semiconfluent monolayer of cells on each coverslip. The medium was replaced with fresh antibiotic free medium with D- mannose (1\%) and inoculated with $25 \mu \mathrm{l}$ of an overnight culture of each $E$ coli isolate grown in peptone water with $\mathrm{D}$-mannose $(1 \%)$. Control strains were included with each assay. After three hours incubation at $37^{\circ} \mathrm{C}$ the medium was replaced with fresh medium and reincubated for a further three hours. Each cover slip was washed thrice with phosphate buffered saline, fixed in $50 \%$ ethanol, dehydrated in absolute ethanol, air dried and Giemsa stained. At least 100 cells from at least 10 microscopic fields were counted and scored for adherent bacilli. The percentage of cells with $>10$ adherent bacilli was recorded and a strain was scored as adherent if at least $40 \%$ of the HEp- 2 cells had adherent bacilli. ${ }^{13}$ The pattern of adhesion ${ }^{14-16}$ of each isolate was also noted and recorded as diffuse, localised, or aggregative adherence. Patient isolates and control strains were coded and tested blind on at least two separate occasions.

SALT AGGLUTINATION HYDROPHOBICITY TEST

The method used was that of Burke and Axon ${ }^{7}$ as adapted from that of Lindahl et al. ${ }^{8}$ Ammonium sulphate solutions were prepared in phosphate buffered saline $(2 \mathrm{mM}$, pH 7.2) over a concentration range of $4 \mathrm{M}$ to $0.02 \mathrm{M}$ in two-fold increments. Twenty five microlitre aliquots of bacterial suspensions, grown on nutrient agar slopes and prepared as described in the buccal cell adhesion assay, were mixed with equal volumes of salt solutions on a clean glass slide. The mixtures were gently rocked for two minutes and the lowest final concentration that gave macroscopic agglutination when read against a dark background was recorded. Strains which autoagglutinated in buffer alone were accorded the value $0 \mathrm{mM}$. In this assay, bacteria with higher surface hydrophobicity agglutinated at lower ammonium sulphate concentrations. ${ }^{8}$

\section{STATISTICAL ANAL YSES}

Data were compared by statistical procedures as appropriate and a $p$ value of $<0.05$ was considered significant. The tests used included: $\chi^{2}$ test, Fisher's Exact test (two-tailed), analysis of variance (ANOVA), distribution free ANOVA (Kruskal-Wallis), Mann-Whitney procedure and linear regression analysis (Statgraphics 2.6; Mercia Software Ltd).

\section{Results}

Rectal biopsy samples from the control group of non-inflammatory bowel disease patients were more likely to include $E$ coli $(13 / 15,87 \%)$ as part of the mucosa associated flora than biopsy samples from patients with new, untreated active colitis (nine of $25,36 \% ; p<0 \cdot 005$ ), active colitis in relapse (eight of $20,40 \% ; p<0.02$ ), or colitis in remission $(26 / 44,59 \% ; p=0 \cdot 11)$. Counts of $E$ coli, and a few rare isolates of other enterobacteria, were low compared with the total flora and were commonly present at levels close to the limit of detection. Mean (SD) counts of enterobacteria $\left(\log _{10} / \mathrm{g}\right.$ tissue) were diminished $(\mathrm{p}<0.05)$ in patients with active disease (noninflammatory bowel disease controls $4 \cdot 32(0 \cdot 92)$, 

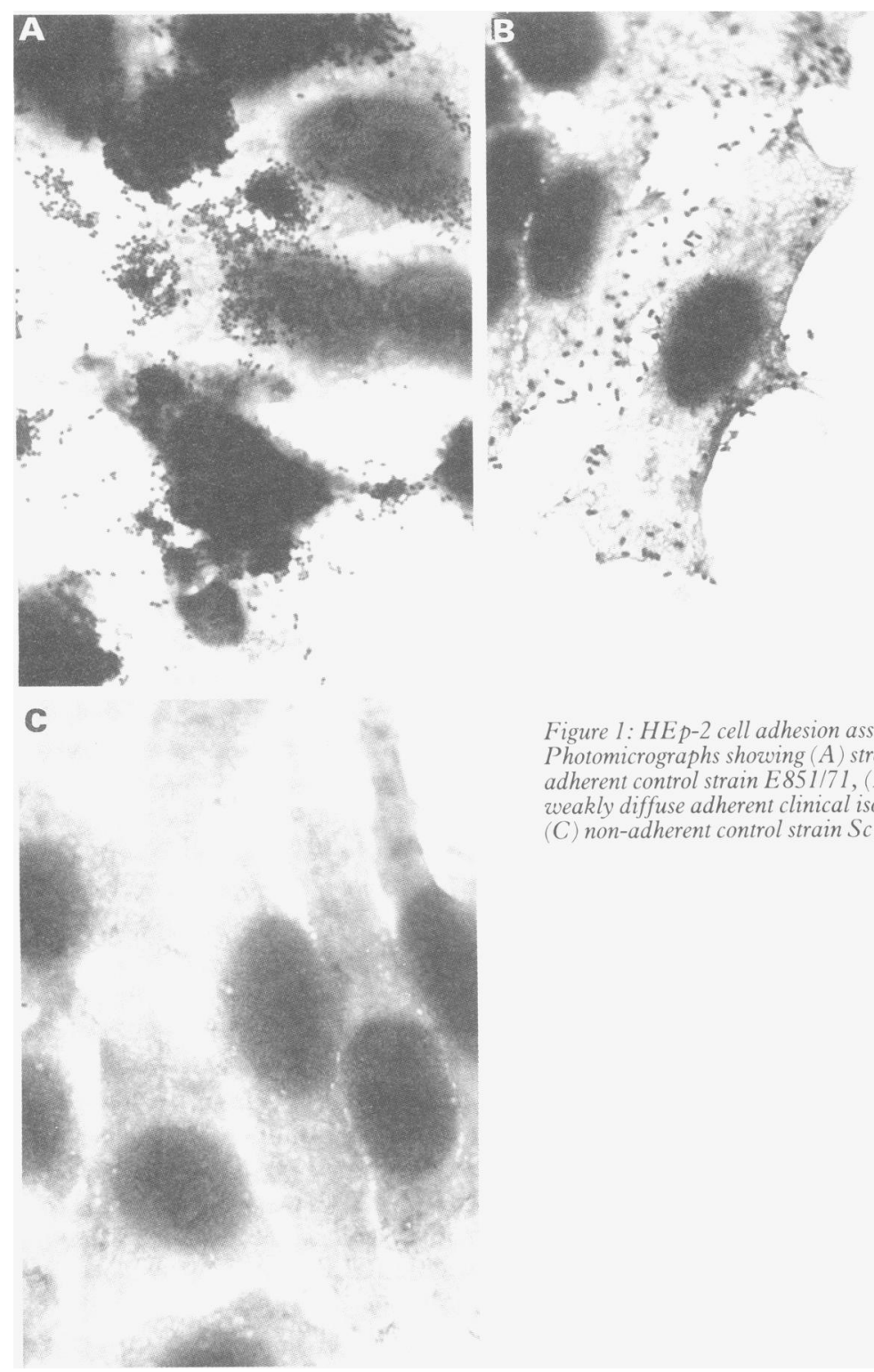

Figure 1: HEp-2 cell adhesion assay: Photomicrographs showing $(A)$ strongly weakly diffuse adherent clinical isolate. (C) non-adherent control strain Sc13.

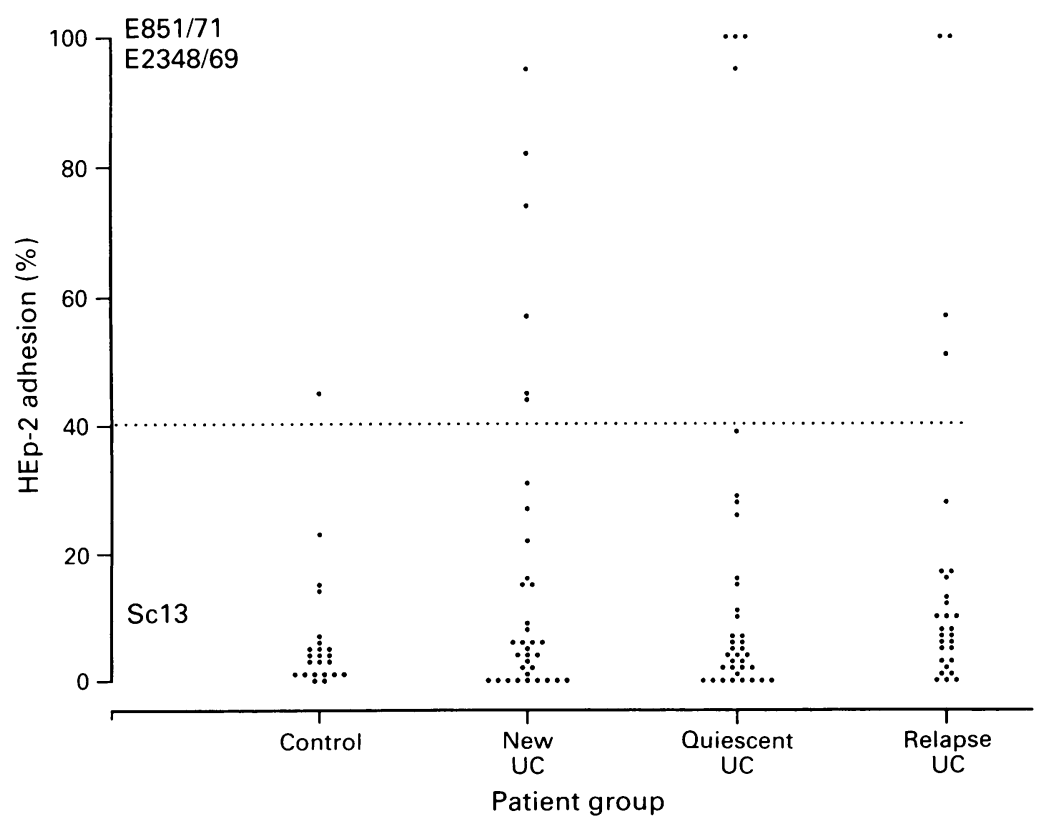

Figure 2: $H E$ p-2 adhesion by Escherichia coli isolates from each patient group, expressed as the percentage of cells with adherent bacteria; control strains are indicated separately. The $40 \%$ level of adhesion is marked. new untreated active colitis $3 \cdot 50(0 \cdot 88)$, colitis in active relapse $3.60(0.96)$, and quiescent colitis $4 \cdot 01(0.99))$. Usually only a single phenotype was found. Thirty nine per cent of biopsy samples from colitic patients contained $\beta$-haemolytic $E$ coli compared with $8 \%$ of samples from noninflammatory bowel disease control patients $(p=0 \cdot 10)$; the distribution of $\beta$-haemolytic strains was unrelated to disease severity.

\section{BUCCAL EPITHELIAL CELL ADHESION ASSAY}

We were unable to discover a donor whose buccal epithelial cells gave reproducible and unambiguous adherence and non-adherence with the appropriate control strains; buccal cells which bound adhesive $E$ coli strains also tended to have a resident salivary flora which was not readily removed by washing. Consequently, the assay was abandoned.

\section{HEp-2 CELL ADHESION}

One hundred and twenty four isolates of $E$ coli were tested for adherence in vitro; 23 were from 13 non-inflammatory bowel disease control patients, 36 from patients with new ulcerative colitis (nine from nine patients with untreated active disease), 29 from patients with relapse of ulcerative colitis (nine from eight patients on presentation) and 36 from 26 patients with quiescent ulcerative colitis.

Figure 1 illustrates the appearance of HEp-2 cells with the strongly adherent control strain E851/71, a weakly diffuse adherent biopsy isolate and the non-adherent control strain Sc13. Both of the positive control strains adhered strongly to HEp-2 cells.

The results of the adhesion assay for each isolate from each patient are shown in Figure 2; the median adherence values (with lower and upper quartiles) were $2 \%(0-8 \%), 2 \cdot 5 \%(0-22 \%)$, $7 \cdot 5 \%(2-18 \cdot 5 \%)$, and $1 \%(0-13 \%)$ for noninflammatory bowel disease controls, new ulcerative colitis, relapsed ulcerative colitis and quiescent ulcerative colitis, respectively. There was no significant difference in the distribution of adherent isolates between any colitis patient group or between patients and non-inflammatory bowel disease controls (Kruskal-Wallis).

Overall, the number of truly adherent isolates (defined as those which attached to $>40 \%$ of the cells) in the control group compared with the colitis groups (one of 23 control versus 15 of 101 colitics) was not significantly different $\left(\chi^{2}=1 \cdot 84\right.$, $\mathrm{p}=0 \cdot 18)$; similarly, no difference was evident when the ulcerative colitis patients were analysed with respect to disease activity.

The majority of isolates showed a diffuse pattern of adhesion. No aggregative adhesion was observed. Only 10 isolates showed localised adhesion and seven of these adhered to less than $40 \%$ of HEp- 2 cells; there was no obvious relationship between the presence of localised adhesion isolates and patient group or disease activity.

SALT AGGLUTINATION TEST

The adherent control strains differed in their 
Non-

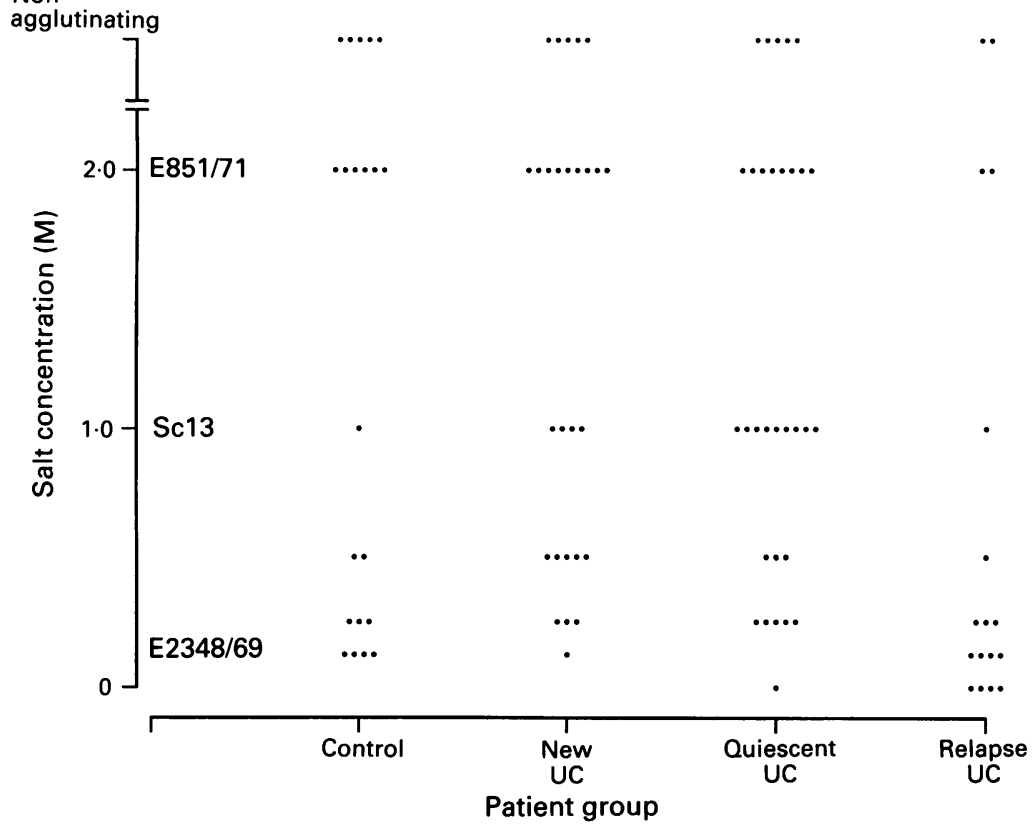

Figure 3: Hydrophobicity of Escherichia coli isolates from each patient group, expressed as the final molar concentration of ammonium sulphate which caused agglutination; control strains are indicated separately.
Figure 4: Correlation of Hep-2 adhesion scores and hydrophobicity for 96 Escherichia coli isolates; control strains are indicated separately.

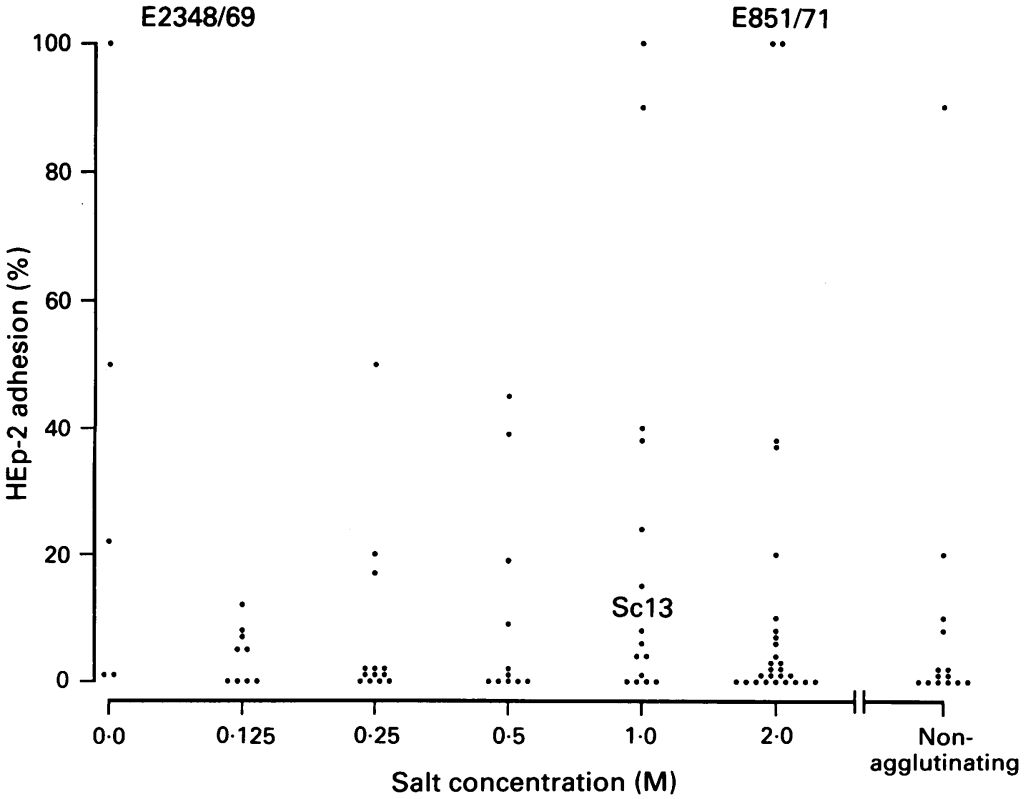

\section{Discussion}

Faecal $E$ coli from patients with ulcerative colitis have been shown to differ from isolates from non-colitics in being markedly more adherent to human epithelial cells in vitro. ${ }^{56}$ This adhesion was not inhibited by D-mannose and was demonstrable with both HeLa cells and human buccal epithelial cells. Mannose resistant adhesion is a common attribute of enteropathogenic and pyelonephritogenic $E$ coli from man and animals. ${ }^{17}$ We were interested to examine the adhesive properties of $E$ coli which we had isolated in studies of the flora closely associated with the rectal mucosa, ${ }^{12}$ a flora in which the expression of adhesins and other adhesion associated characteristics might be expected to be favoured or prerequisite, and to compare our results with those reported for faecal isolates.

We found HEp-2 cells were easy to grow and manipulate and gave reliable results in the adhesion studies; this is the cell line recommended $^{14-16}$ for adhesion assay of enteropathogenic and other pathogenic $E$ coli. In contrast, we were unable to show consistent adhesion of control strains to any preparation of buccal epithelial cells from a panel of eight donors. The success of this assay is dependent upon the choice of buccal cell donor (Burke, personal communication) and this casts some doubt on its usefulness and reproducibility; it is clearly a difficult technique to standardise between laboratories. Giaffer and colleagues ${ }^{17}$ have recently used a slightly modified buccal cell adhesion assay to show that $E$ coli from ulcerative colitis and Crohn's disease patients were significantly more adhesive than isolates from a control group, but that this property was independent of disease activity, anatomical site and treatment. We followed standard protocols for the preparation of bacterial suspensions for adhesion and hydrophobicity assays because the expression of adhesins is known to be affected by nutrient and growth conditions ${ }^{18}$; however, as repeat assays with both control strains and patient isolates confirmed, such properties are otherwise quite stable phenotypic markers.

$E$ coli from ulcerative colitis patients were marginally more adhesive for HEp-2 cells than those from non-inflammatory bowel disease control patients, regardless of disease activity. The magnitude of difference, however, was far less marked than that reported by others. ${ }^{5}$ Mannose resistant adherent $E$ coli isolates from colitics were also reported to possess higher surface hydrophobicity. ${ }^{7}$ Our results with $E$ coli isolates from the rectal mucosa do not support either finding, a paradoxical result for a tissueassociated flora.

We noted a discrepancy between the salt agglutination test result for the control strain E851/71 reported by Burke and Axon ${ }^{7}$ and that reported here; their strain agglutinated at $0.4 \mathrm{M}$ (final concentration) whereas our strain agglutinated at $2 \mathrm{M}$. In contrast, results for strain Sc13 were comparable. We obtained our strain E851/71 from a different source.

Our isolates of $E$ coli were from the rectal mucosa and were presumably closely associated with, if not actually attached to, the epithelium; 
loosely adherent bacteria were removed from the tissue by the vigorous washing procedure. The complex mechanisms controlling such bacteria tissue associations are obscure ${ }^{19}$ Although some of our $E$ coli isolates were hydrophobic and others expressed mannose resistant adhesins for HEp-2 cells, these two properties were not related. Properties such as surface hydrophobicity and adhesion to epithelial cells are important properties of bacteria which colonise mucosal epithelia, ${ }^{19}$ but the mechanisms involved are clearly more complex than those described by these two assays alone. It would be interesting to compare the adherent and hydrophobic properties of faecal and mucosaassociated $E$ coli isolates from individual patients in order to resolve the discrepancies between the data presented here and those reported by others. In contrast with the differences in adhesins and hydrophobicity, the mucosal isolates from colitic patients were more commonly $\beta$-haemolytic than were isolates from noninflammatory bowel disease controls, as has been well documented for faecal isolates from colitics $^{31720}$ and also for Crohn's disease. ${ }^{17}$

In our studies of the mucosa associated microflora of the rectum in ulcerative colitis we showed that $E$ coli were isolated relatively infrequently during active disease and that their numbers increased with clinical improvement. ${ }^{12}$ This was not related to any change in adhesive properties. The control group of non-inflammatory bowel disease patients had a higher carriage rate of $E$ coli than either patients with active colitis or colitis in remission. Both the frequency of detection and the numbers of $E$ coli in the mucosaassociated flora increased during treatment and with clinical improvement. ${ }^{12}$ These data would argue against a pathogenic role for $E$ coli in ulcerative colitis. It is conceivable, however, that the normal mucosa associated enterobacteria are displaced by a more sparse population of pathogenic phenotypes which do not express mannose resistant adhesins.

We are most grateful to Drs S Scotland, M McConnell and B Rowe of the Division of Enteric Pathogens, Central Public Health Laboratory, Colindale for provision of control strains and for advice and confirmation of the adhesion and hydrophobicity assays. Our thanks to Dr M J Hill for advice and encouragement and to Dr D Newell for help and advice with tissue culture and to and to Dr DNewell for help and advice with tissue culture and to Dr A Doyle (ECACC) for providing the cell lines. Mrs E R Elphick National Association for Colitis \& Crohn's Disease (NACC), the
PHLS Board, and the British Digestive Foundation (Wolverhampton Appeal) for financial support. We are also grateful to the following pharmaceutical companies for donations in support of these studies: Astra (UK), Biorex, Glaxo, Kabi Pharmacia (UK), and SmithKline Beecham.

1 Kirsner JB, Shorter RG. Recent developments in "nonspecific" inflammatory bowel disease. $N \mathrm{EnglF} \mathrm{Med} 1982$; 306: $837-48$.

2 Gorbach SL, Nahas L, Plaut AG, Weinstein L, Patterson JF, Levitan R. Studies of intestinal microflora. V. Fecal microbial ecolog in ulerative colitis and r. bial ecology in ulcerative colitis and regional enteritis: relationship to severity of disease and enterology 1968; 54: 575-87.

Cooke EM. Properties of strains of Escherichia coli isolated from the faeces of patients with ulcerative colitis, patients with acute diarrhoea and normal persons. $\mathcal{F}$ Pathol Bacterio 968; 95: 101-13.

4 Tabaqchali S, O'Donoghue DP, Bettelheim KA. Escherichia coli antibodies in patients with inflammatory bowel disease. Gut 1978; 21: 353-9.

5 Dickinson RJ, Varian SA, Axon ATR, Cooke EM. Increased incidence of faecal coliforms with in vitro adhesive and invasive properties in patients with ulcerative colitis. Gut 1980; 21: 787-92.

6 Burke DA, Axon ATR. Ulcerative colitis and Escherichia col with adhesive properties. F Clin Pathol 1987; 40: 782-6.

7 Burke DA, Axon ATR. Hydrophobic adhesins of $E$ coli in ulcerative colitis. Gut 1988; 29: 41-3.

8 Lindahl M, Faris A, Wadström T, Hjertén S. A new test based on 'salting out' to measure relative surface hydrophobicity of bacterial cells. Biochim Biophys Acta 1981; 677:471-6.

9 Brauner A, Katouli M, Tullus K, Jacobson SH. Cell surface hydrophobicity, adherence to $\mathrm{HeLa}$ cell cultures and haemagglutination pattern of pyelonephritogenic haemagglutination pattern of pyelonephritogenic

10 Burke DA, Clayden SA, Axon ATR. Sulphasalazine does not select for Escherichia coli with adhesive properties in ulcerative colitis. Lancet 1988 ; ii: 966 .

11 Burke DA, Axon ATR, Clayden SA, Dixon MF, Johnston D Lacey RW. The efficacy of tobramycin in the treatment of ulcerative colitis. Aliment Pharmacol Therap 1990; 4: 123-9.

12 Hartley MG, Hudson MJ, Swarbrick ET, Hill MJ, Gent AE Hellier MD, et al. The rectal mucosa-associated microflora in patients with ulcerative colitis. $\mathcal{F}$ Med Microbiol 1992; 36 96-103.

13 Scotland SM, Gross RJ, Rowe B. Laboratory tests for enterotoxin production, enteroinvasion and adhesion in diarrhoeagenic Escherichia coli. In: Sussman M, ed. The virulence of Escherichia coli: reviews and methods. London: Academic Press, 1985: 395-405.

14 Cravioto A, Gross RJ, Scotland SM, Rowe B. An adhesive factor found in strains of Escherichia coli belonging to the traditional infantile enteropathogenic serotypes. Curr Microbiol 1979; 3: 95-9.

15 Scaletsky ICA, Silva MLM, Trabulsi LRT Distinctive patterns of adherence of enteropathogenic Escherichia coli to HeLa of adherence of enteropathogenic

16 Nataro JP, Kaper JB, Robins-Browne R, Prado V, Vial P, Levine MM. Patterns of adherence of diarrheagenic Escherichia coli to HEp-2 cells. $\mathcal{F}$ Paediatr Infect Dis $1987 ; 6$ : 829-31.

17 Giaffer MH, Holdsworth CD, Duerden BI. Virulence properties of Escherichia coli strains isolated from patients with inflammatory bowel disease. Gut 1992; 33: 646-50.

18 Parry SH, Rooke DM. Adhesions and colonization factors of Escherichia coli. In: Sussman $M$, ed. The virulence of Escherichia coli: reviews and methods. London: Academic Press, 1985: 79-155.

19 Savage DC. Effects on host animals of bacteria adhering to epithelial surfaces. In: Savage DC, Fletcher $M$, eds. Bacterial adhesion: mechanisms and physiological significance. New York: Plenum Press, 1985: 437-63.

20 Cooke EM, Ewins SP, Hywel-Jones J, Lennard-Jones JE. Properties of strains of $E$ coli carried in different phases of ulcerative colitis. Gut 1974; 15: 143-6. 